\title{
Managerial Ethics and Organizational Effectiveness: The Nigerian Experience
}

\author{
Nwinyokpugi, N. Patrick ${ }^{1}$, Dr. B.M. Nwibere ${ }^{2}$ \\ ${ }^{1,}$ Department of Office \& Information Management, University of Science \& Technology, Port Harcourt, \\ Nigeria \\ ${ }^{2}$ Department of Management, University of Port Harcourt, Nigeria
}

\begin{abstract}
The study examined the effect of managerial ethics on organizational effectiveness. The sample for the study consisted of 231 managers from 46 randomly selected organizations in Nigeria. A purposive choice of the south-south region was made to enable the research reach and possible generalization. The study utilized both quantitative data (questionnaire) and qualitative data (interview). The Multiple Regression Model using the Statistical Package for Social Sciences (SPSS) version 15 was utilized for the analysis of data. Our finding revealed a positive and significant relationship between managerial ethics and organizational effectiveness. Based on this finding, it was concluded that managerial ethics had a significant positive effect on organizational effectiveness.
\end{abstract}

Keywords: Merit, Integrity, Justice, Managerial Ethics, Organizational Effectiveness

\section{Introduction}

Nigerian economy has strong potential for a sustainable growth and development in view of its abundant and variety skilled human and extensively rich natural resources. Nigeria is a country blessed with favourable vegetation, alluring topography, vast deposit of mineral resources and a large reservoir of resourceful manpower. It is obvious that its population size (about 140 million people) and some inherent dynamics should make it not only the largest market in black Africa but also a haven for foreign investors. Its land is so fertile that I most often think that 'if one plants' a finger it might grow into a full fledged human being'. Unfortunately, this situation which would have been transformed for the general good of all is now turned into a deteriorating macro economic environment, and unstable political system characterized by wide spread poverty $(70 \%$ of Nigerians are in this class), disappointingly low return on private and public sector investment, deteriorating infrastructure resulting in poor service delivery, low industrial capacity utilization and high unemployment. Available statistics points to the fact that the performance of Nigeria in overall development since independence (47 years ago) has been abysmally poor and confronts the world with a most perplexing paradox that one can best describe as "Resource Development Disequillibrium" occasioned by vicious circle of economic waste and deep ulcerated economic injuries inflicted on the country by its resource managers.

Our leaders have basked in the sun of insensitivity to the realities of our people, squandered resources and opportunities, devalued our dignity, deflated our pride, humiliated our personality as a country, mortgaged our future and eroded all the advantages we have as a people. The custodian of state powers have ran down our basic institutions, made corruption an art at one time and at another made corruption the prerogative and exclusive preserve of a few, while fragrant violation of the rule of law is the fashion. The negative consequences of this arrogance and misguided deployment of power opportunities and resources is vividly clear for everyone to see. Discrimination and nepotism are said to exist in employment, granting of distributorship, sale of government companies, properties, parastatals and agencies. There is alleged pay off to some members of our legislative houses; electoral officers manipulate elections either for "Ghana must go" or get friends into leadership positions; elected officials indicted in bribery scam; law enforcement officers aiding and abetting corruption; companies and individuals evading taxes, religious leaders involved in unholy acts; companies and individual trading in sub-standard and expired products for financial gains; frequent fire outbreaks at government offices to cover fraud, to mention but a few. There are also reports about high school principals who receive a few Naira for students' admission, enlist ghost teachers on the payroll, and some teachers/Lecturers who see their female students as an added incentive to their regular pay and thus, sleep with these female students to make them pass their examinations.

Ritual killings and political assassinations; political riggings and widespread cases of advance fee fraud popularly called "419". They hear these people, when caught, although in very rare cases, giving excuses such as "Everyone else does it, Opportunity comes but once, hence you have to take advantage of every opportunity nowadays, it is my own share of the national cake". In this kind of situation, even the few that were hitherto ethical in their behaviour are compelled to join the train, that is if they cannot help it. 
On the business front, the situation is horrible. There is the almost daily disclosure of unethical business practices in Nigeria. Profiteering, window dressing, juggling of books, bribery and corruption prevail. Some women are alleged to wield "bottom power" very effectively to gain promotion to higher positions, or win contracts and supplies. Some young beautiful ladies in our banks are alleged to use their bodies in order to meet deposit targets. There are also incidences of managers who manipulate cash flow figures to secure a needed loan from banks (window dressing), salesmen who pad the expense account to help themselves or worse still, buy gift for a girl friend or even the worker who stretches out his job and original products being carefully diluted, adulterated and sold to unsuspecting customers. Ifedi (1983:7), corroborates this point when he posit that "seeking preferential treatment, kick-backs to purchasing officers, pay-offs to government officials, pricerigging between suppliers and contractors and collusion in contract bidding, underbidding, with substitution of inferior workmanship and materials are rampant with some companies." What this suggests therefore is a state of almost complete ethical and moral breakdown thus, raising questions about the moral value of public officials and enterprise managers in our society today and whether ethics significantly affect the performance of our businesses and by extension, national development? Perhaps one can therefore venture to say that the most serious managerial challenge facing Nigeria's quest for development is the issue of ethics. Ethics is a problem not only for managers but also for almost every facet of our society today. However, there is also the question of what criteria should guide ethical conduct and behaviour? Also, the issue of whether ethical absolutes exist? These are fundamental questions that should be looked at objectively and devoid of any emotionalism that tends to surround the subject.

From the above discussion, it is obvious that there have been a significant number of studies on the concepts of managerial ethics and organizational effectiveness. The benefits resulting from positive managerial ethics have received much attention in literature especially in advanced countries like France, America, Japan, United Kingdom to mention a few. This growth of scholarly activity within the organizational framework is among the most significant development in the sociology of knowledge. Yet, despite a background of intensive studies on the subject, something remains lacking: little empirical evidence exists in the developing countries, especially Nigeria as regards the relationship between managerial ethics and organizational effectiveness. It would be relevant to note that if the research findings from western contexts are to become more valuable and relevant for Nigerian organizations, it is necessary for researchers to use Nigerian organizations for organizational research. To fill this gap in the literature, this study examines the relationship between managerial ethics and organizational effectiveness.

\section{Review of Related Literature}

Nigeria faces crises not only of development and governance but also crises of ethical referents capable of providing guiding principles for politics and business. This explains why predatory use of state power and fraudulent business practices have been such recurrent phenomena at almost all periods of Nigeria's history. Predatory habits of political and administrative office-holders manifest themselves in the proclivity towards plundering state resources and extracting illegal payment from its citizens. Fraudulent behaviour is also basic in the private sector. This behaviour manifests itself in a number of frauds which ranges from" cutting costs, spending corporate and shareholder money on personal expenses, manipulating financial records for personal needs, to corporate frauds such as granting of unauthorized overdrafts and loans, forged cheques, posting fictitious credit, fraudulent transfer and withdrawal, outright theft, suppression of cash/cheques advances for fraud, bogus investment opportunities, financial market frauds and money laundering that are meticulously planned and intricate in their execution" (Babalola, 2005: 284). We will start the discussion here with the basic question "what is ethics?"

\section{I. The Concept of Ethics}

Ethics is used in a variety of ways, and there is no agreed definition of what it is. Some define it broadly, as an application of principles such as justice and truthfulness to the business world, or as a set of laws relating to competition which guarantee fairness in the market and restrict practices that violate the rights of employees, share-holders, and customers. For others, business ethics is only a relative means or tool to safeguard the objectives of business, that is to say, higher profits and productivity. However, according to Robert Solomon, business ethics is about achieving a life honour and integrity. Some decades ago, sociologists Raymond Baumhart asked business people, "What does ethics mean to you? Among their replies were the following: "Ethics has to do with what my feelings tell me is right or wrong;" "Ethics has to do with my religious beliefs;" "Being ethical is doing what the law requires;" "Ethics consists of the standards of behaviour our society accepts;" "I don't know what the word means." These replies might be typical of our own.

The meaning of "ethics" is hard to pin down, and the views many people have about ethics are shaky. Like Baumhart's first respondent, many people tend to equate ethics with their feelings. But being ethical is clearly not a matter of following one's feelings. A person following his or her feelings may refrain from doing 
what is right. In fact, feelings frequently deviate from what is ethical (Velasquez et al., 1987). Nor should one identify ethics with religion. Most religions, of course, advocate high ethical standards. Yet if ethics were confined to religion, then ethics would apply only to religious people. But ethics applies as much to the behaviour of the atheist as to that of the saint. Religions can set high ethical standards and can provide intense motivations for ethical behaviour. Ethics, however, cannot be confined to religion nor is it the same as religions. Being ethical is also not the same as following the law. The law often incorporates ethical standards to which most citizens subscribe. But laws, like feelings, can deviate from what is ethical. The pre- Civil war slavery laws in Nigeria is grotesquely an obvious example of laws that deviate from what is ethical. Finally, being ethical is not the same as doing "whatever society accepts." In any society, most people accept standards that are, in fact ethical. But standards of behaviour in society can deviate from what is ethical. An entire society can become ethically corrupt.

The Nigerian Police Force, as at today, is a good example of a morally corrupt system. Moreover, if being ethical was doing "whatever society accepts," then to find out what is ethical, one would have to find out what society accepts. To decide what we should think about abortion, for example, we would need to take a survey of the Nigerian society and then conform our beliefs to whatever society accepts. But no one ever tries to decide an ethical issue by doing a survey. Further, the lack of societal consensus on many issues makes it impossible to equate ethics with whatever society accepts. For some people abortion is ethical but for many others, it is not.

What, then, is ethics? Ethics (from latin ethica from the Ancient Greek, ri "moral philosophy" from the adjective of ethos "custom, habit), a major branch of philosophy, is the study of values and customs of a person or group. It covers the analysis and employment of concepts such as right and wrong, good and evil, and responsibility (Wikipedia, 2007). It is divided into three primary areas: meta-ethics (the study of the concept of ethics), normative ethics (the study of how to determine ethical values), and applied ethics (the study of the use of ethical values). For our present purpose, ethics would be considered from two broad perspectives. First, ethics refers to well based standards of right and wrong that prescribe what humans ought to do, usually in terms of rights, obligations, benefits to society, fairness, or specific virtues. Ethics, for example, refers to those standards that impose the reasonable obligations to refrain from rape, stealing, murder, assault, slander, and fraud. Ethical standards also include those that enjoin virtues or honesty, compassion, and loyalty. And, ethical standards include standards relating to rights, such as the right to life, the right to freedom from injury, and the right to privacy. Such standards are adequate standards of ethics because they are supported by consistent and well-pounded reasons. Secondly, ethics refers to the study and development of one's ethical standards. As mentioned above, feelings, laws, and social norms can deviate from what is ethical. So it is necessary to constantly examine one's standards to ensure that they are reasonable and well-founded. Ethics also means, then, the continuous efforts of studying our own moral beliefs and our moral conduct, and striving to ensure that we, and the institutions we help to shape, live up to standards that are reasonable and solidly based.

Although there is no agreement on the increase or otherwise of the level of unethical, unprofessional or corrupt behaviour, there is evidence to suggest that more publicity is now being given to such behaviour than in the past. In both the developed and developing countries, the public's perception of widespread wrongdoing has helped to undermine public trust and confidence in governments and business.

\subsection{Ethics and the Nigerian State}

Questions of ethics in Business and government have been prominent in the news in recent years. Inside trading, deceptive advertising, bribery and kickbacks, price description, falsification of public statements, illegal campaign contributions, and other scandals have created an impression that Nigerian business managers use illegal means to gain competitive advantage, increase profits, or improve their personal positions. Most organisations lie to their customers in an attempt to gain competitive advantage. Most Nigerian managers believe that profits are more important than product safety. The shocking revelations by NAFDAC will buttress this point. Most often, one has to bribe a cashier to get paid; one has to offer money to a file clerk to make sure that your documents are not wrongly filed; one has to bribe a doctor or nurse in a public hospital to receive treatment; it has been alleged that some ministers are expected to bribe the members of the National Assembly before their ministry's budget is approved or worse still, before they are even given the opportunity to defend their budget proposals; you need to bribe police officers at check points before you can pass; you need to bribe the police officers before you are granted bail (even when it is stated in bold terms on the bail bonds that bail is suppose to be free); you have to bribe the pump attendants at fuel stations to fill your tank etc.

In the government and private sector, the demand for 10 percent kickback or more of any contract sum is an accepted practice. Many Nigerian enterprise managers are known to have made decisions in order to enrich themselves rather than to optimize government or enterprise interest. An executive in any decision to purchase an equipment for example, is suppose to take such factors as parts, cost, quality, delivery time, operating cost etc. into consideration before a decision to purchase the equipment is reached. However, most Nigerian 
managers are known to have ignored these important facts in order to receive kickbacks of 10 percent or more of the cost of the equipment. Most others are also known to have awarded major contracts to themselves at exorbitant prices. Often Governors, Legislators, enterprise managers and employees alike are known to be the owners of companies that contracts to construct roads, buildings, or offer any other services for their employersgovernment or organization. To this end, they find it difficult to enforce quality or engage in hard bargain. They most often supply inside information to their companies on the lowest and highest bids already received as well as approve jobs that are overtly below specified standards.

One of the daily Newspapers in the country once had this on its front page under the title " The Nigerian and Corruption" "Keeping an Average Nigerian from Being Corrupt Is Like Keeping a Goat from Eating Yam" This is a bad way of putting it. A goat needs yam because it is food for goats. A Nigerian does not need corruption; neither is corruption necessary nourishment for Nigerians. It is totally false to suggest, as we are apt to do, that Nigerians are different fundamentally from any other people in the world. Nigerians are corrupt because the system under which they live makes corruption easy and profitable; they will cease to be corrupt when corruption is made difficult and inconvenient.

The aim of ethics is to identify both the rules that should govern people's behaviour and the "goals" that are worth seeking. All ethical decisions are guided by the underlying values of the individual, ethical climate in the industry, and behaviour of management. Values are principles of conducts such as caring, honesty, keeping promises, pursuits of excellence, loyalty, fairness, integrity, respect for others, and responsible citizenship. Most people would agree that all these values are admirable guidelines for behaviour. However, ethics becomes a more complicated issue when situations dictate that one value over rule another. Ethics is the system of rules that governs the ordering of values (Bateman and Snell, 1999: 154). An ethical issue is a situation, problem, or opportunity in which an individual must choose among several actions that must be evaluated as right or wrong (Ferrell and Fraedrich, 1997). Ethical issues arise in every facet of life; we concern ourselves here with business ethics in particular. Business ethics comprises the moral principles and standards that guide behaviour in the world of business (Ferrell and Fraedrich 1997).

When people make decisions that are judged by ethical criteria, these questions always seem to get asked: why did he/she do it? Good motives or bad ones? His responsibility or someone else's? Who get the credit, or the blame? So often responsibility for an unethical act is placed squarely on the individual who commits it but the environment has a profound influence, as well. Most employees and managers in the Nigerian workplace are increasingly finding themselves facing ethical dilemmas; situations in which they are required to define right and wrong conduct. For example, should they "blow the whistle" if they uncover illegal activities taking place in their company? Should they follow orders with which they do not personally agree? Do they give an inflated performance evaluation to an employee whom they like, knowing that such an evaluation could save that employee's job? Do they allow themselves to play politics, or boot- lick in the organization, if it will help their career advancement?

What constitutes good ethical behaviour has never been clearly defined. And in recent years, the line differentiating right from wrong has become even more blurred. Most Nigerian employees see people around them engage in unethical practices. Besides, individuals have differing personal ethical codes; thus Nigerian organization must be explicit irrespective of corporate ethical standards and expectations. Some companies advocate the "golden rule": "Do unto others, as you would have them do unto you". However, others argue that current or accepted business practices should govern behaviour. Their motto is "Everyone else does it". A more extreme attitude in Nigeria is that organizations should seek every possible advantage without regard for tradition, social laws and customs - a "might equals right" philosophy. Finally, some believe that ethics should be determined by intuition, that is, by doing whatever is felt right?

Most foreign companies like IBM use a guideline for business conduct that requires employees to determine whether under the "full glare of examination by associates, friends, and family, they would remain comfortable with their decisions". One suggestion is to imagine how a subject would feel if he/she saw his/her decision and its consequences on the front page of a Newspaper (Messick and Bazerman, 1996). This "light of day or "sunshine" ethical framework could be deemed to be extremely powerful and the fear of exposure may compel people more strongly in some cultures than in others. In Asia and America, for example, anxiety about losing face often makes Asian and American executives resign immediately if they are caught in ethical transgressions, or if their companies are embarrassed by revelations in the press. In contrast, in Nigeria, exposed executives and elected officials most often respond with indignation, Intransigence, stonewalling, and an everyone - else - does - it self defense, or by non admission of wrongdoing, giving no sign whatever of resignation as is the case with the current bribery scandal rocking the National assembly. Partly because of legal tradition, the attitude often is: never explain, never apologize, and do not resign, even if the entire world knows exactly what happened. Do not admit the mistake nor accept the consequences.

Following from the above, it is an ongoing challenge to maintain consistent ethical behaviour by all employees. What are some of the danger signs that most Nigeria organization may be allowing or even 
encouraging unethical behaviour among its people? Many factors create a climate conducive to unethical behaviour including:

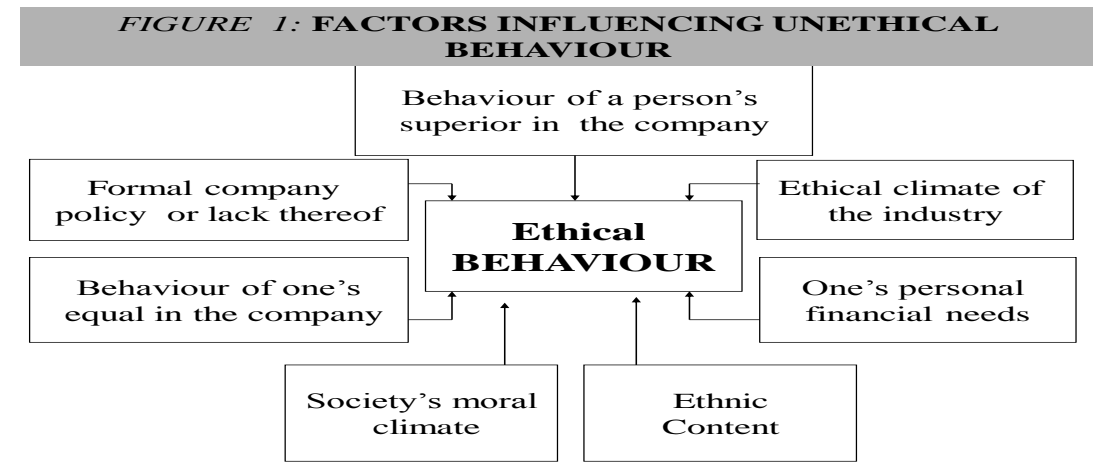

Source: Baridam, D.M. and Nwibere, B.M. (2008) Understanding and Managing Organizational Behaviour.

Sherbrooke Associates,

Port Harcourt.

As can be seen from the figure above, ethics is not shaped only by society and by individual development and virtue, it also may be influenced by company work environment. The ethical climate of an organization refers to the process by which decision are evaluated and made on the basis or right and wrong (De George, 1990). Others factors identified in the literature as enhancing unethical behaviour include:

- $\quad$ the behaviour of a man's superior in a company;

- $\quad$ ethical climate of the industry;

- $\quad$ the behaviour of a man's equals in the company;

- $\quad$ personal financial needs;

- $\quad$ excessive emphasis on short term revenue over long term considerations;

- $\quad$ failure to establish a written code of ethics;

- $\quad$ a desire for simple, “quick fix" solution to ethical problems;

- $\quad$ an unwillingness to take an ethical stand that may impose financial cost,

- $\quad$ consideration of ethics solely as a legal issue or a public relation tool;

- $\quad$ lack of clear procedure to handle ethical problems and

- $\quad$ response to the demand of shareholders at the expense of other constituencies (Cooke, 1991).

Ethical code must be carefully written and tailored to individual companies' philosophy. Most ethical codes address subjects such as employee conduct, community and environment, shareholders, customers, suppliers and contractors, political activity, and technology. To make an ethical code effective, Nigerian managers must:

i) involve every one, meaning every person who has to live with it, in writing the statement;

ii) have a corporate statement, but also allow separate statements by different units throughout the organization;

iii) keep it short and therefore easily understood and remembered;

iv) do not make it too corny - make it something important , that people really believe; and,

v) set the tone at the top, having executives talk about and live up to the statement..

Ethical codes should always match with practice, or become ridiculous exercise in futility. When reality differs from the statement - as when a motto says people are our most precious asset, or a product is the finest in the world, but in fact people are treated poorly, or product quality is weak - the statement becomes a joke to employees rather than a guiding light.

\subsection{Dimensions of Ethics}

Nigerian Managers can improve ethical behaviours through ethics programs. According to Bateman and Snell (2002), Ethics programs can range from compliance-based to integrity-based. Compliance - based ethics programs are designed by corporate counsel to prevent, detect, and punish legal violations. Compliancebased programs increase surveillance, control people and impose punishments on wrongdoers. Program elements include establishing and communication of legal standards and procedures, assigning high-level managers to oversee compliance, auditing and monitoring compliance, reporting criminal misconduct, punishing wrongdoers, and taking steps to prevent offense in future. Such programs reduce illegal behaviour and help the 
company stay out of court, but they do not create a moral commitment to ethical conduct; they merely ensure moral mediocrity. On the other hand, integrity-based ethics programs go beyond the mere avoidance of illegality; they are concerned with the law but also with instilling in people a personal responsibility for ethical behaviour. With such a program, companies and people govern themselves through a set of guiding principles that they embrace. The Nigerian manager of today needs to create an ethically-healthy climate for his or her employees, where they can do their work productively and be able to objectively differentiate right from wrong.

\subsection{Business and Ethics}

The purpose of ethics in business is to direct business men and women to abide by a code of conduct that facilitates, if not encourages, public confidence in their products and services. Philosophers and others disagree about the purpose of a business in society. For example, some suggest that the principal purpose of a business is to maximize returns to its owners, or in the case of a publicly traded concern, its shareholders. Thus, under this view, only those activities that increase profitability and shareholder value should be encouraged. Some believe that the only companies that are likely to survive in a competitive marketplace are those that place profit maximization above everything else. However, some point out that self-interest would still require a business to obey the law and adhere to basic moral rules, because the consequences of failing to do so could be very costly in fines, loss of licensure, or company reputation.

The economist Milton Friedman was a leading proponent of this view (Wikipedia, 2007). Other theorists contend that a business has moral duties that extend well beyond serving the interests of its owners or stockholders, and that these duties consist of more than simply obeying the law. They believe a business has moral responsibilities to so-called stateless people who have an interest in the conduct of the business, which might include employees, customers, vendors, the local community, or even society as a whole. They would even suggest that this even includes rights of governance. In America, the Protestant work ethic at one time formed the basis of good business relationship. A Person's word was his bond and business could be counted on with a handshake. Personal integrity and reputation mattered. But in business, there is also a "dog eat dog" mentality. To the victor goes the spoil. Somehow, when it comes to business, there is such an emphasis on success, that morals and ethics take a back seat.

The larger an organization, the more complex the strategy and operations, the easier it becomes to stretch standards and change the numbers to reflect what is desired, rather than what is. Meeting the numbers seems more desirable than sticking to reality. Besides, one might reason that "reality" or "truth" is really just a question of which version, which perspective. Here is the way one cynical executive puts it. "Let's be honest. We lie and our colleagues lie to us. That's how human beings operate. People prefer to tell each other what they want to hear. I don't need perfect people, I need successful people who can think for themselves and get the job done. If they need to tell a little white lie, I can live with that." Perhaps, a look at the various ethical perspectives will be most crucial at this stage.

\subsection{Ethical Perspectives}

The two main classifications of ethical perspectives are Consequentialist and Deontological. Consequentialist ethics focuses on the consequences of the action. It takes the perspective that ethical choices are contextual and shoube determined by the beneficial desired outcome (Botes, 2000). On the other hand, the Deontological ethics emphasize judging the act itself rather than the consequences of the action (Pollock, 1994). Justification of an act based on moral principles, rather than on the outcome of the act (Sandel,1982). Since the ethical perspectives are often contradictory and contrary, this may lead to conflict and lake of consensus among organizational members in the decision making process. When resolving ethical problems or issue, it is important to seek some way of avoiding conflict and promote a mutual understanding about ethical decisions in the organization. By analyzing the effect of each perspective, it is possible to be objective about the impact of each decision.

The Justice or Fairness Ethics is the approach that most people had been using. Rather than focusing on consequences, Deontological or Rights Ethics emphasize the right thing to do or duty whether or not it produces beneficial outcomes (Webb, 2004). The basic principle of justice or fairness ethics is that "Individuals should be treated the same, unless they differ in ways that are relevant to the situation in which they are involved"(Andre and Velasquez,1990). The principle seeks to answer the question: Is this decision fair and just to all concerned?

The Utilitarian or Benefit Approach: Utilitarianism, a form of consequentialist ethics promotes doing what provides the greatest good for the greatest number. The principle considers those actions that produce the greatest of benefits over harms most as appropriate (Moberg and Velasquez, 2004). Since this approach requires that individual needs be sacrificed for the good of everyone, the company can and would deprive of a few individual right for the good of the majority (Geva, 2000). 
Ethics of Rights or Deontology constitutes an ethical perspective in terms of which ethical decisions are made on the basis of universal principles and rules, and in an impartial and verifiable manner with a view to ensuring the fair and equitable treatment of all people. The principle requires that people are treated the same unless there are morally relevant differences between them.

The Ethics of Virtue or Care upholds certain ideals such as excellence or dedication to the common good, towards which all individuals should strive and which allow the full development of humanity (Velasquez et al.,1987). It constitute an ethical approach that focuses on the needs in terms of which involvement, harmonious relations and needs of others play an important part in ethical decision making in each ethical situation (Botes, 2000). Virtues are considered to be attitudes, dispositions, and character traits that allow individuals to be and to act in ways that develop humanity's full potential including that capacity to care. The principle examines aspects of what is ethical and develops moral virtues in individuals and communities.

The Ethics of Common Good or Beneficence focuses on attitudes, dispositions, or character traits that enable individual to be and to act in ways that develop human potentials these include: honesty, courage, faithfulness, trustworthiness, and integrity (Botes 2000). It requires that individuals in organization identify and further common goals while accepting the autonomy of individuals to pursue their own interests. While this may appear a common sense approach to resolving organisational issues, it is important to realize that different people have differing ideas about what is good. The question then arises whose view of goods should be accepted? Most Americans, for example, view society as comprised of autonomous individuals who have the freedom to pursue their own goal and interest without interference from others. In this individualistic culture it is difficult, if not impossible, to convince people that they should sacrifice some of their freedom, goals, and self-interest for the sake of the "common good" (Elsbernd,2005)

The Golden Rule: The golden rule states "Do unto others as you would have then do unto you" the basic premise being that other people would like to be treated the way you would like to be treated yourself. Alessandra and O'Connor (1996) argue that this basic premise makes 'the golden rule' flawed and inadequate in equitable treatment of individuals. What appear to be the same treatment of employees may not result in equitable outcomes.

Platinum Rule: Alessandra and O'Connor (1996) propose, instead, an alternative to the "golden rule," they call the "platinum rule". The "platinum rule" states "treat others the way they want to be treated". By considering how individuals want to be treated, 'The Platinum Rule' takes into account the feelings of others. The focus shifts from "This is how I liked to be treated, so I'll treat everyone the same way" to "Let me first understand how people want to be treated and I will treat them that way."

\subsection{Criticisms of the Various Approaches and perspectives}

No approach in any decision-making situation is without some challenges. The problem with the Utilitarian Approach is defining those outcomes that should be considered "good". Similarly, with common good ethics the challenge is identifying and agreeing on common goals. In the right approach determining which values comprise what is "right" is especially difficult. Seeking harmonious relations and the need of others may be counterintuitive for business organizations. To overcome these difficulties, a company can use more than one approach. As the organization contemplate its future products and services, the company can simultaneously carry out one or more approaches to moral reasoning that would be complementary to each other. Identification of the cooperate common goals while recognizing individual needs, goals and interest, and determining the appropriate outcomes for employees would be one way of overcoming shortcomings in each approach.

Figure 2: Conceptual Framework

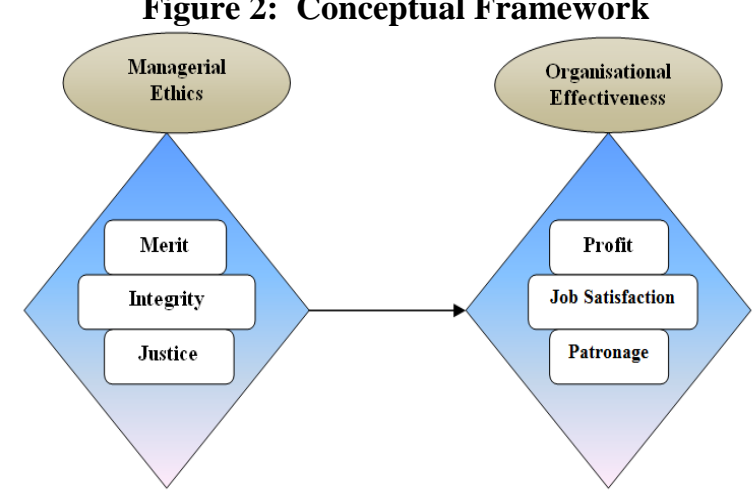

An effective organization can be defined broadly as one that achieves its purpose by meeting the wants and needs of the stakeholders, matching its resources to opportunities, has high market patronage, ensure employee job satisfaction, adapting flexibly to environmental changes and creating a culture that promotes commitment, creativity, shared value and mutual trust (Amstrong, 2001:258). 


\section{Research Methodology}

The study is correlational and was conducted as a cross sectional survey. The study units were individual organizational members and analysis carried out at the micro level. The population consisted of 588 managers and supervisors of selected 46 firms from six states of the South-south region in Nigeria(akwa Ibom, bayelsa, Cross Rivers, Delta, Edo, and Rivers), and the sample size determined using the krejcie and morgan (1970) sample size table was 234 (Sekaran, 2003). Respondents were sampled using the simple random sampling technique. After data cleaning, 231 copies of the instrument were considered useful for the analysis.

Managerial Ethics was operationalized into three major empirical referents which depict actual ethical values adopted in the workplace; these include: Merit, Integrity and Justice. These were each measured on a 7item instrument which assessed feelings and opinions based on the availability, practice and adoption of these ethical value systems. A 5-point likert type scale ranging between (1) strongly disagree, to (5) strongly agree, was used to express level of agreement with each of the items. Organisational Effectiveness was measured on a 12-item instrument and also scaled on a likert scale of (1) strongly disagree, to (5) strongly agree. For the test of reliability of the scales the following cronbach alpha coefficients were obtained: Managerial Ethics $(0.904)$ while for Organisational Effectiveness (0.970) in accordance with Nunnaly (1978) model which recommends a bench mark of 0.70 . Content validity was adopted as the instrument was first examined by various scholars and necessary corrections made.

\subsection{Research Findings}

For our primary analysis, frequencies and descriptives were used, the use of percentages, mean scores and standard deviations which illustrated the nature of the distribution, first with the demographic data and then the study variables. The results showed that $85 \%$ of the respondents were male while the remaining $15 \%$ were female, this figure which as observed by Asawo (2009) identifies the inequality of gender distribution in all the organisations so studied. $30 \%$ of the supervisors are holders of diploma certificates, $60 \%$ make up first degree certificate holders while only $10 \%$ make up masters certificate holders. None of the respondents had obtained a Ph.D. degree.

The univariate analysis shows the empirical referents of Managerial Ethics, starting with Merit with a low mean score of 2.6401 (standard deviation is 1.45521), Integrity has a mean score of 2.4768 (standard deviation is 1.35617), while Justice carries a mean score of 3.0025 (standard deviation is 1.37405) which is the highest. Managerial Ethics as the latent predictor variable carries a mean score of 3.1394 (standard deviation is 1.31472) while Organisational Effectiveness, the criterion variable, carries a mean score of 2.7065 (standard deviation is 0.87959 )

Figure 3: Linear Regression

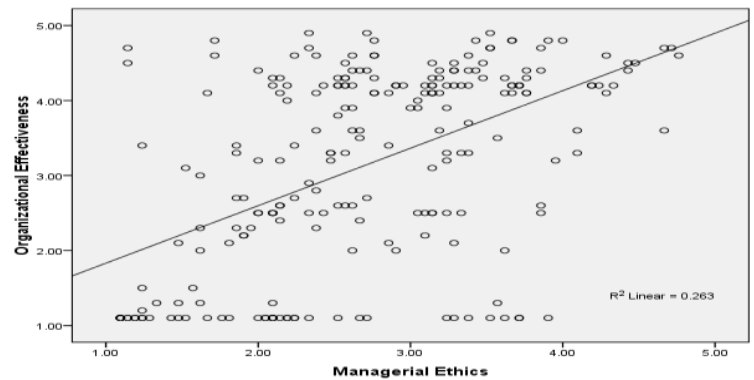

The study also used linear regression to examine the relationship between Managerial Ethics and Organisational Effectiveness. The diagram shows a positive relationship between Managerial Ethics and Organisational Effectiveness $R^{2}$ value of 0.263 .

Table 1 showing bivariate analysis using Spearman's Rank Order Correlation Coefficient.

\begin{tabular}{l|l|c|}
\hline $\begin{array}{l}\text { Managerial } \\
\text { Ethics }\end{array}$ & Organisational Effectiveness \\
\hline Merit & Correlation Coefficient & 0.276 \\
\hline & P-value & 0.000 \\
\hline & $\mathrm{N}$ & 231 \\
\hline Integrity & Correlation Coefficient & 0.170 \\
\hline & P-value & 0.010 \\
\hline & $\mathrm{N}$ & 231 \\
\hline Justice & Correlation Coefficient & 0.523 \\
\hline & p-value & 0.000 \\
\hline & $\mathrm{N}$ & 231 \\
\hline
\end{tabular}


The table shows the strength and direction of the relationship between the measures of managerial ethics and organizational effectiveness. Merit has the low rho value, 0.276 , but a $p$-value of $0.000(p<0.05)$ which is less than our level of significance. This indicates a significant relationship, Integrity which has the lowest rho value of 0.170 and a $\mathrm{p}$-value of $0.010(\mathrm{p}<0.05)$ which is still less than 0.05 level of significance. Justice carries the highest rho value of 0.523 and with a p-value of $0.000(\mathrm{p}<0.05)$ less than 0.05 level of significance.

All bivariate relationships indicate significant positive relationships and portray Managerial Ethics as a relevant variable and concept in the pursuit of Organisational Effectiveness. The model is as a result of the findings from our bivariate relations.

\section{Conclusion and Recommendations}

One major limitation of this study is that it did not consider the effect of environmental factors. We acknowledge the effect of environmental factors on our framework. This factor is however, held constant.

Selecting an appropriate process for decision-making is critical to the development of an ethical organizational culture. The use of a decision making model provides organizations a framework for conceptualizing and solving various types of ethical problems (Geva, 2000). The idea that commitment to ethical decision making could be essential to managerial success should be emphasized within the organization. This will have the effect of shifting the focus from individual development towards organizational interests. In most organization there is an over reliance on organizational codes of ethics to direct and determine ethical behavior in the organization. This places the onus on the individual rather than upon the organization, with no expectations beyond the individual for the development of an ethical culture.

Individuals are manipulated into accepting the "need" for commitment, and that commitment is judged by their display of certain behavioural competencies and their espousal of certain values. Linking this to their acceptance of increased uncertainty and insecurity in the employment relationship tends to invite a very emphatic critique based on principles of ethical humanism. Furthermore, there is no need to establish and evaluate moral agency among those involved in development (French and Bell 1990). With the development of a more ethical organizational culture, the question of ethics ceases to be an individual issue, becoming instead a corporate responsibility

While decision depends on the experience, intelligence, capability, and integrity of the decision maker (Stainer, 2004), ethical decision-making is not the sole purview of the leader. Ethical approaches to decisions, interactions, conduct, and business practices must be infused throughout the organization. Creating a code of conduct or a code of ethics does not ensure ethical behaviour within the Organization (kamberg, 2001). It is applied ethics or ethics in practice that can make a difference. Applying ethics and values as a leadership imperative requires one to sort out individual values. An approach for doing this is to identify individual moral beliefs, legal system, organizational or professional code of ethics. It is important to determine if the situation can be resolve by checking our own values individually. Our individual moral basis for decision making is applicable in situations where the decisional approach will not clash with the organization's standards, values and ethics. However, when the situation where a decision is needed does not respond to nor call for a moral individual-based response it is important to have a collaborative organizational process in place that recognizes justice and fair play, employee integrity and meritocracy.

\section{References}

[1] Ifedi, Chuma "Business Ethics in Nigeria," Daily Times, Wednesday, March 23, 1983

[2] Babalola, S.S. (2005) "Positive Leadership: Antidote of Fraud to Fraudulent Practice in Corporate Organisations" Quoted in Adebayo Olukoshi et al. (Eds) Beyond the State: Nigeria's Search For Positive Leadership. University of Ibadan Press, Ibadan.

[3] Valesquez, M. C.; Andre, T.; Shanks, S.J. and Meyer, M.J. (1987) Thinking Ethically: a framework for moral decision making". Makkula center for applied ethics. Retrieved May 19,2005 http://www.scu.edu/ethics/practicing/decision/thinking.html.

[4] Wikipedia, (2007)" Business Ethics". Free Encyclopedia.

[5] Bateman, Thomas S. and Scott A. Snell. (1999). Management: Building a Competitive Advantage , 4th Ed. Boston: Irwin/McGraw-Hil

[6] Ferrell O. C., and Freadrich, J., (1997), Business Ethics: Ethical decision and cases. Centage lerarning.

[7] Messick, D. M., and Bazerman, M. H. (1996). Ethics for the 21st century: A decision making approach. Sloan Manage. Rev.37: 9-22

[8] Baridam, D.M. and Nwibere, B.M. (2008) Understanding and Managing Organizational Behaviour. Sherbrooke Associates, Port Harcourt.

[9] De George (1990) Business Ethics $6^{\text {th }}$ ed, Prentice Hall

[10] Cooke, R. M., (1991), Experts in Uncertainty: Opinion and Subjective Probability in Science (Environmental Ethics and Science Policy Series)

[11] Bateman, T.S. \& Snell, S.A. 2002 Management: Competing In The New Era. 3rd Ed. Chicago : Irwin. 575 P. 19

[12] Botes, A. (2000) A Comparison between The Ethics of Justice And The Ethics Of Care. Journal of Advanced Nursing, Vol 32, No 5, PP1071-1075. 
[13] Pollock III, P. H. (1994). Issues, Values, and Critical Moments: Did" Magic" Johnson Transform Public Opinion on AIDS?. American Journal of Political Science, 426-446.

[14] Sandel, M. (1982) Liberalism and The Limits Of Justice. Cambridge University Press, Cambridge.

[15] Webb, A. (2004). Manager's Commitment to Goals in a Strategic Performance Management System. Contemporary Accounting Research, 21(4): 925-958.

[16] Andre, C. and Valasquez, M. (1990) "Justice and Fairness". Issue in ethics, Vol 3, No 2, Retrieved April 10, 2006 http://www.scu.edu/ethics/publications/iie/v/3n2

[17] Moberg, D.J. and Valesquez, M. (2004) The Ethics of Mentoring. Business Ethics Quarterly, Vol 14, PP95-122.

[18] Geva, A. (2000) "Moral Decision Making In Business: A Phase-Model”. Business Ethics Quarterly, Vol 4, PP773-803.

[19] Elsbernd, M. (2005) "Social Ethics". Theological Studies, Vol 66, No 1, PP137-158.

[20] Alessandra, A and O'Connor M. J. (1996 ).The Platinum Rule: Discover The Four Basic Business Personalities and How They Can Lead You To Success. Warner Books, New York.

[21] Armstrong M., (2001), Handbook of Human Resources Management and Practice.

[22] Krejcie \& Morgan (1970), Determining Sample Size for Research Activities: Educational and Psychological Measurement, 30, pp. 607-610).

[23] Sekaran U. (2003): Research methods for business; fourth edition. John Wiley \& sons, pp. 294

[24] Asawo, S.P (2009) Spiritual Leadership and Workers Commitment, Phd Thesis in Management, Rivers State University of Science and Technology.

[25] Stainer, L. (2004) ethical dimensions of management decision making. Strategic Change, Vol 136, PP333-342.

[25] Kamberg, M. (2001) "Making Ethical Business Decisions". Women in Business, Vol 532, PP 22-25.

[27] Burke, F. (1999) ethical decision making: Global concerns, frameworks, and approaches. Public Personnel Management, Vol 28, PP529-539. 